\title{
Foodborne Parasitic Diseases in the Neotropics - a review
}

\author{
F. CHÁVEZ-RUVALCABA 1 , M. I. CHÁVEZ-RUVALCABA², K. MORAN SANTIBAÑEZ ${ }^{3}$ J. L. MUÑOZ-CARRILLO ${ }^{4}$, \\ A. LEÓN CORIA ${ }^{5}$, R. REYNA MARTÍNEZ ${ }^{6 *}$
}

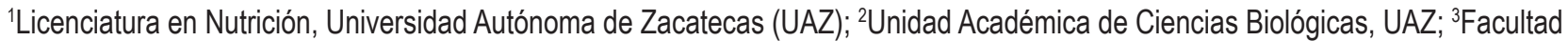
de Ciencias Biológicas, UANL; ${ }^{4}$ Facultad de Odontología, Universidad Cuahutémoc plantel Aguascalientes; ${ }^{5}$ Universidad de Calgary Faculty of Sciences, University of Calgary, Canada; ${ }^{\star}$ Facultad de Ciencias Químicas, Universidad Autónoma de Nuevo León (UANL),

E-mail: gustavo.reynamr@uanl.edu.mx
\end{abstract}

Article info

Received December 23, 2020

Accepted February 8, 2021

\section{Summary}

Within the Universal Declaration of Human Rights, it is stated that everyone has the right to an adequate standard of living, which ensures, as well as their family, health and well-being, and food, thereby ensuring adequate nutrition. One of the major threats to overcome this is to ensure food security, which becomes particularly challenging in developing countries due to the high incidence of parasitic diseases. The World Health Organization (WHO), considers it one of the main causes of morbidity, closely linked to poverty and related to inadequate personal hygiene, consumption of raw food, lack of sanitary services, limited access to drinking water and fecal contamination in the environment. It is estimated that more than a fifth of the world's population is infected by one or several intestinal parasites, and that in many countries of Central and South America the average percentage of infected people is $45 \%$, being Taenia solium, Echinococcus granulosus, Toxoplasma gondii, Cryptosporidium spp, Entamoeba histolytica, Trichinella spiralis, Ascaris spp, Trypanosoma cruzi and Fasciola hepatica some of the most important ones in the neotropics. One of the main reasons why these diseases are difficult to control is the ignorance of their lifecycles, as well as symptoms and current epidemiology of the disease, which contributes to a late or erroneous diagnosis. The present work aims to discuss and make public the current knowledge as well as the general characteristics of these diseases to the general audience.

Keywords: Foodborne; parasitic; diseases; helminths; protozoa

\section{Introduction}

Foodborne illnesses are a group of conditions produced by ingestion of food and are caused by a broad range of chemical contaminants, bacteria, viruses, parasites and biotoxins, and are often referred as neglected diseases. On a global scale, they constitute important public health issues due to their incidence, serious sequelae and mortality, new forms of transmission, vulnerable population groups, increased resistance of causative agents to antimicrobial compounds, as well as the negative effects on the economy attributable to costs in health services, productivity, demands and consumer's confidence (Marin et al., 2020; Sander et al., 2020).

According to the World Health Organization (WHO) parasitic diseases, resulted in 48.4 million cases and $n$ 59,724 deaths annually, resulting in 8.78 million Disability Adjusted Life Years (DALYs), and it is estimated that $48 \%$ of these parasitic diseases were foodborne (Torgerson et al., 2015).

\footnotetext{
* - corresponding author
} 
The zoonotic potential of foodborne pathogens and their ability to cause several diseases or even death is sufficient to recognize the seriousness of the situation (Heredia \& García, 2018)

For a foodborne illness to occur, the pathogen must be present in the food. However, the mere presence of the pathogen does not mean that the disease will occur. In most cases of foodborne parasitic illnesses (OPS/WHO, 2014):

The parasite must be present in sufficient quantities to cause infection.

The parasite must be able to subsist on the food. That is, the food must have intrinsic characteristics that keeps the agent under favorable conditions.

Food must remain at an appropriate temperature long enough for the parasite to survive.

Enough (portion) of the food containing the pathogen must be ingested so that the individual's immunological response is surpassed.

Rates of parasitic contamination differ from one country to another, and even between regions within the same country. The increase of human population and urbanization, the globalization, cultural preferences and eating habits have led to an increase in zoonotic infections incidence. Nowadays, there is a worldwide increase in the consumption of raw or slightly cooked vegetables, which also increases the risk of foodborne infections (Berrouch et al., 2020; Trevisan et al., 2019; Heredia \& García, 2018). Millions of people contract foodborne diseases daily. Parasites can be present in food and water and can cause illness. They range in size from small, single-celled organisms to worms visible to the naked eye. Their life cycles also vary. While some parasites use a permanent host, other parasites go through a series of developmental stages using different hosts, whether humans, or other animals. These parasitosis can cause a wide variety of illnesses, from uncomfortable symptoms to debilitating disorders and possibly death (USDA, 2017).

The tropical climate of many developing countries favors the proliferation of pests and naturally occurring toxins, as well as the risk of contracting parasitic diseases, including worm infestations. Parasitic diseases often result in high burdens of disease in low- and middle-income countries and are frequently transmitted to humans via contaminated food. These parasitosis are often chronic, with long-term sequelae (Trevisan et al., 2019; Torgerson et al., 2015) Water usage in the food industry include activities such as: irrigation, washing of fresh produce, and processing. Water scarcity means increased utilization of wastewater for these previous activities, increasing the chance of fresh produce contamination (Trevisan et al., 2019).

The climate of the neotropics (which extends from Mexico to southern Brazil, encompassing all Central America, the Caribbean, and almost all South America), favors the presence of a great diversity of food-borne parasitic diseases. The scarcity of studies carried out in this geographical region prevents the exact epidemiology of these diseases from being established. In addition, it is not mandatory to notify public health authorities about most parasitic diseases, for which the real prevalence or incidence of the diseases is not known (WHO, 2018). In the present work we focus on nine of the most important neotropic foodborne parasites: Taenia solium, Echinococcus granulosus, Toxoplasma gondii, Cryptosporidium spp., Entamoeba histolytica, Trichinchiella spiralis, Ascaris spp., Trypanosoma cruzi and Fasciola hepatica (Fig. 1).

\section{Taenia solium}

Taenia solium is a cestode parasite found mainly in humans and pigs. It causes taeniasis on its adult form, and cysticercosis on its metacestode larval form (Lightowlers et al., 2016). This disease is related to poor sanitary conditions, open defecation, and presence of free roaming pigs. Humans are the definitive hosts of $T$. solium, carrying the adult tapeworm, and pigs are the intermediate hosts infected with the metacestode larval stage (cysticercus). Humans acquire $T$. solium tapeworm infection (taeniasis) by consumption of undercooked pork containing viable cysticerci. Pigs contract porcine cysticercosis (PCC) by ingestion of $T$. solium eggs contained in human feces from tapeworm carriers, the larval stage establishes in the central nervous system. (Coral-Almeida et al., 2015). T. solium is endemic across Latin America, sub-Saharan Africa (SSA), and South Asia. In 2014, the parasite was ranked first on the global scale of foodborne parasites and was recently re-estimated as a leading cause of deaths from foodborne diseases (de Coster et al., 2018). Recent studies shown that $31.5 \%$ of epilepsy cases could be due to NCC in endemic settings. The Foodborne Disease Burden Epidemiology Reference Group (FERG) estimated that NCC associated epilepsy accounted for approximately 2.8 million disability-adjusted life years (DALYs) globally in 2010 (Dixon et al., 2019). An estimated between 1998 - 2011, found that cysticercosis-related hospitalizations in the USA represented a rate of 8.03 per million people. But these estimations are only available for some geographic regions. Latest reports have found occurrence of human taeniasis in Belize, Colombia, Costa Rica, Cuba, Guadalupe, Guatemala, Haiti, Honduras, Mexico, Panama and Venezuela. Meanwhile in Ecuador the burden of human neurocysticercosis indicated an incidence rate per 10000 person $0.23 \%$ for NCC. However, in the neotropics, taeniasis it is considered endemic, and it is very likely that is a major unrecognized health problem, due the lack of data and underreported cases of cysticercosis in Central America and the Caribbean (Braae et al., 2017; Coral-Almeida et al., 2020).

The eggs of $T$. solium contain a six-hooked larva (hexacanth) called the oncosphere. When the egg hatches, this oncosphere is released into the intestine. Gastric fluid and intestinal fluid dissolve the embryophore shell and releases the unactivated oncosphere. The oncosphere is then stimulated by the intestinal fluid to activate and to tear open the enclosing oncospheral membrane. This activated oncosphere can penetrate the intestinal wall and reach the target tissues where it transforms into a cysticercus. This is the lar- 


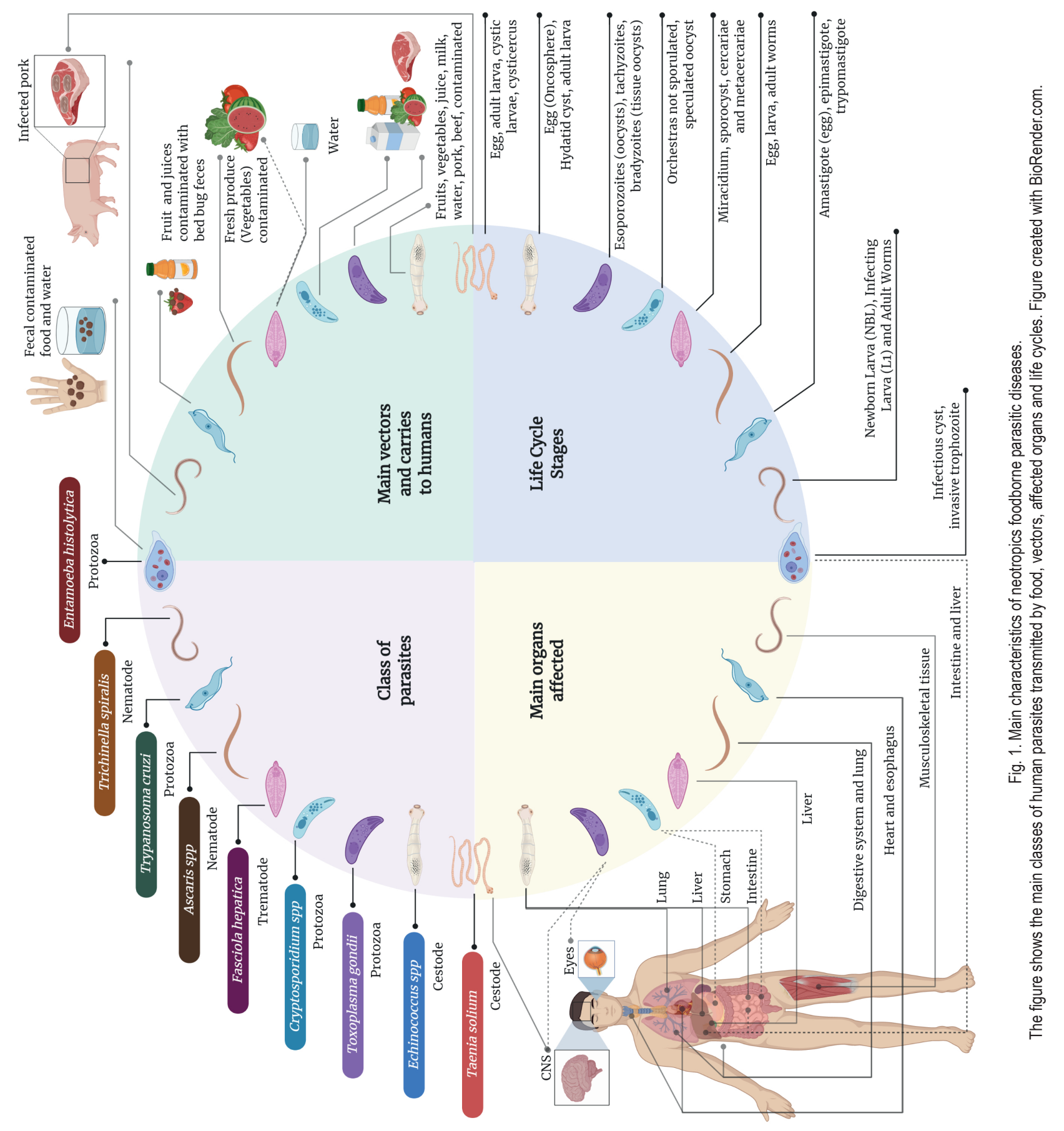


val stage of the parasite that consists of a fluid-filled sac containing an invaginated scolex. As this happens, the parasite produces a variety of molecules, which modulate the host immune response to evade parasite destruction. The adult $T$. solium measures between 2 to 4 meters in length (Chile et al., 2016).

Life cycle takes place when pigs ingest human stools containing T. solium eggs and develop the larval infection, in humans, the ingestion of pork infected with the cystic larvae will develop into intestinal taeniasis. When human ingest contaminated pork, the cyst's scolex evaginates by action of the bile and intestinal enzymes, and affixes to the small intestine mucosa, here, the worm grows and develops segments or proglottids which mature as they become more distal to the scolex. The tapeworm is hermaphroditic, and after fertilization the final segments are gravid and full of mature eggs. These infective eggs are expelled with the feces. Once ingested by a suitable host (pig), the embryos contained in the eggs hatch, cross the intestinal wall, and are carried by the bloodstream to all body tissues where they establish as the larval stage or cysticercus (Garcia et al., 2014).

Intestinal taeniasis is usually asymptomatic, while cysts in the nervous system produce neurocysticercosis (NCC) which is the most common clinical manifestation. This manifestation varies depending on the number of cysts, location, size and stage of the parasite, as well as the inflammatory response of the host. Parasitic larvae located in the parenchyma of the brain most frequently manifest with seizures (Garcia et al., 2014). NCC diagnosis is based on tests detecting antibodies against $T$. solium cysticerci (Coral-Almeida et al., 2015). NCC can also be diagnosed using a combination of imaging and serological techniques. Microscopic examination of fecal samples containing Taenia eggs has been used in epidemiological studies, however detection by microscopy is limited to genus identification since eggs of different Taenia species are indistinguishable (Lightowlers et al., 2016).

Some commercial anthelmintics have shown efficacy in the treatment of taeniasis, including albendazole, praziquantel and niclosamide (Haby et al., 2020). In the pig host, vaccines are available including TSOL18, alongside anthelmintic treatment using oxfendazole (CystiTeam Group, 2019).

\section{Echinococcus granulosus}

Human echinococcosis is a zoonotic disease result from infection with the larval stage of several species of the genus Echinococcus, infection develops after consumption of eggs from the canid definitive host. Foodborne transmission occurs through contamination of food or water with parasite eggs, however, the proportion infections through food consumption has not yet been estimated, although these eggs have been found in salads. Echinococcosis may appear in two main forms: cystic echinococcosis (also known as hydatidosis) and alveolar echinococcosis. Cystic echinococcosis (CE) is one of the most prevalent zoonotic diseases in South America caused by the larval stage of the cestode Echinococcus granulosus, which is responsible for $95 \%$ of cases of human echinococcosis, with a global burden estimated 1 million DALYs. (Wen et al., 2019; Torgerson et al., 2014).

It should be noted that exists two indigenous neotropical species: E. vogeli and E.Oligarthrus; which differ in size and shape from $E$. granulosus. The possible occurrence of $\mathrm{CE}$ in humans observed in South America, might have been caused by E. vogeli or, less likely, by $E$. oligarthrus. However, human infections with these indigenous species have been rarely diagnosed (D'Alessandro \& Rausch, 2008).

Echinococcosis has a cosmopolitan distribution and represents a major public health problem in some regions. In South America is endemic in parts of Argentina, Bolivia, Brazil, Chile, Peru, and Uruguay (Larrieu \& Zanini, 2012). It is prevalent in low-income, livestock-raising communities. The prevalence of cystic echinococcosis increases with age, and women are affected more frequently than men; this might be related to domestic activities that bring them in closer contact with dogs through feeding, herding, or milking livestock (Agudelo et al., 2016).

E. granulosus adult worms are very small (2 to $7 \mathrm{~mm}$ long) and consist of a scolex, a neck, and only a single proglottid at each stage of development (immature, mature, and gravid). The scolex has four lateral suckers and the rostellum is non-retractable and armed with a double crown of $28-50$ recurved hooks. The eggs are ovoid (30 $\mu \mathrm{m}-40 \mu \mathrm{m}$ diameter), consisting of a hexacanth embryo (oncosphere or first larval stage) surrounded by several envelopes, the most noticeable one being the highly resistant keratinized embryophore, which gives the egg a dark striated appearance. The outer capsule quickly disappears once the eggs are liberated from the host (Bushura, 2019). The eggs of Echinococcus are morphologically indistinguishable to those of other tapeworms of the genus Taenia. The metacestode (second larval stage) consists of a bladder with an outer acellular laminated layer and an inner nucleated germinal layer, which may give rise by asexual budding to brood capsules. Protoscoleces arise from the inner wall of the brood capsules. The structure and development of the metacestode differs between species (Garcia, 2007).

The adult $E$. granulosus resides in the small intestine of the definitive host (dogs or other canids). The worms may survive in the host for up to 20 months, and each gravid proglottid contains about $100-1500$ eggs. After the gravid proglottids and eggs are passed in the feces, they may be swallowed by an intermediate host (sheep, goat, swine, cattle, horses, camel, among others, including humans). After ingestion, eggs hatch in the duodenum and release six-hooked oncospheres. The released oncospheres penetrate the intestine and are carried via the bloodstream, where they are filtered out in the various organs. The most common localization in humans are the liver (60 to $70 \%$ of cases) and lungs. In these organs, the oncosphere develops into a thick-walled hydatid cyst that enlarges gradually, producing protoscolices and daughter cysts that fill the cyst interior. When animals that serve as intermediate hosts are slaughtered, the viscera may not be disposed of 
properly and may be consumed by animals that serve as definitive hosts. The adult worms then develop in the intestine of the definitive host (Wen et al., 2019; Garcia, 2007).

Cystic echinococcosis is usually asymptomatic unless complications occur. The rate at which symptoms appear typically depends on the location of the cyst. Rupture with resultant infection or anaphylaxis, fistula development with adjacent structures (e.g., in the biliary tract, intestine, and bronchus) or mass effect on neighboring structures are the major mechanisms by which a cyst usually becomes symptomatic. Most patients ( $40 \%$ to $80 \%$ of cases) have a single cystic lesion located in a single organ. The liver is affected in $70 \%$ of the cases, the right lobe more commonly than the left. The lung is the next most frequently affected organ and is affected in about $20 \%$ of the cases (Agudelo et al., 2016).

Imaging techniques are essential for diagnosis, with the relatively inexpensive and portable ultrasound (US) widely used to diagnose $\mathrm{CE}$ or AE liver lesions; X-ray is used for lung cysts. Serologic tests are available, including the enzyme linked immune transfer blot (EITB) test, which apparently offers greater sensitivity and specificity than do the enzyme-linked immunosorbent assay (ELISA) and arc-5 double-diffusion assay (DD5). Serologic differentiation between cystic and alveolar echinococcosis, involving recombinant larval antigens has also been used (Garcia, 2007).

Several options are available for treatment of echinococcosis, including surgery, puncture-aspiration injection-respiration (PAIR), and chemotherapy (benzimidazoles). Surgery is generally considered the treatment of choice for a complete cure. In cases where multiple cysts are present in several different sites or in patients with a high surgical risk, PAIR and chemotherapy are considered appropriate options, either together or separately. Long-term follow-up with imaging is required to evaluate the efficacy of treatment, as serology results may remain positive for years even after successful treatment (Agudelo et al., 2016; Garcia, 2007).

\section{Toxoplasma gondii}

Toxoplasma gondii is an obligate intracellular protozoan parasite that infects up to a third of the world population, it is one of the most common parasites in man and warm-blooded animals (Wang et al., 2017). The infection is acquired mainly by ingestion of food or water contaminated with oocysts that cats shed or by consuming undercooked or raw meat that contains cysts. The socioeconomic impact of toxoplasmosis on human suffering and the cost of caring for sick children, especially those with mental retardation and blindness, are enormous. To date, up to 287 genotypes have been described worldwide and these derive from the severity of the disease.

Toxoplasmosis is present in every country and seropositivity rates range from less than $10 \%$ to over $90 \%$. The annual incidence of congenital toxoplasmosis worldwide was estimated to be 190,100 cases (Togerson \& Mastroiacovo, 2013). In the United States and the United Kingdom, it is estimated that between $16 \%$ and $40 \%$ of the population is infected, while in Central America, South America and continental Europe, infection estimates range between $50 \%$ and $80 \%$ (Hill \& Dubey, 2002). Brazil has a very high rate of $T$. gondii infection in humans. Up to $50 \%$ of primary school children and $50-80 \%$ of women of childbearing age have antibodies against $T$. gondii (Dubey et al., 2012). In Colombia, the prevalence in the human population varies between $30 \%$ and $60 \%$ and is related to the high density of urban stray cats. In Yucatan, Mexico, the infection incidence is over $70 \%$ in humans and other animals (Valenzuela et al., 2019).

Studies of genotypes of $T$. gondii have found three major multilocus genotypes, types I, II, and III. However, most isolates from South America, do not fit into these the three major lineages, showing a high level of diversity, especially in the wild Amazonian area, with many unique polymorphisms that may represent a potential risk for human health. Severe toxoplasmosis with multiorgan failure and higher rate and severity of retinochoroiditis have been linked to atypical strains acquired from the Amazonian rainforest, sometimes after the consumption of infected food (Robert-Gangneux \& Dardé, 2012).

There are three infectious stages of $T$. gondii for all hosts: sporozoites (in sporulated oocysts as an environmentally resistant form), tachyzoites (individually or in groups and with rapid multiplication) and bradyzoites (tissue oocysts with slow multiplication), in their complex life cycle, cats can shed millions of oocysts after ingesting just one bradyzoite or tissue cyst, and many tissue cysts can be present in an infected mouse (Hill \& Dubey, 2002). Humans become infected by ingesting tissue cysts in undercooked or raw meat or by ingesting food and water contaminated with oocysts from infected cat feces. Oocyst-borne infections can be more serious than tissue cyst-induced infections.

In most adults the disease is asymptomatic, but it can cause blindness and mental retardation in children with congenital infection, this occurs when a woman becomes infected during pregnancy. Infections during the first trimester are more serious than those acquired in the second and third trimester. At first there is a generalized infection in the fetus, later, the infection clears the visceral tissues and can be localized to the central nervous system (Wang et al., 2017). Mild disease may consist of slightly impaired vision, while severely ill children may have the full tetrad of signs: retinochoroiditis, hydrocephalus, seizures, and intracerebral calcification. Of these, hydrocephalus is the least common, but most dramatic lesion of toxoplasmosis. The most common sequela of congenital toxoplasmosis are eye conditions. Toxoplasmosis could be a devastating disease in immunosuppressed individuals, in which encephalitis is the most dangerous manifestation of the disease. Concentration methods (eg, flotation in a high-density sucrose solution) are often used as detection methods because of the number of $T$. gondii oocysts in cat feces. In meat, the best method is the detection of tissue bradyzoites through the digestion of meat with trypsin or pepsin. The diagnosis in humans is performed by either biological, serological, histological, or molecular methods, or 
by combination of these (Hill \& Dubey, 2002).

Although there are many drugs available, the treatment of choice is the combination of pyrimethamine with sulfadiazine, which can control the rapid replication phase (acute phase of the disease) but does not influence cysts. For cysts treatments with hydroxynaphthoquinone (atovaquone) and azithromycin seem to be the treatment of choice (Zamora et al., 2020).

\section{Cryptosporidium spp.}

It is an enteric protozoan parasite that can be transmitted to humans from animals, other humans, contaminated food, or water, and tends to cause waterborne outbreaks (Vanathy et al., 2017). Cryptosporidium cysts and oocysts are usually excreted in large quantities in the feces of infected hosts, accounting for the largest waterborne outbreaks reported between 1998 and 2012. The low infectious dose for these protozoa means that the associated risk to public health is increased. Foods can also be contaminated by oocysts and cysts due to poor hygiene conditions during transformation or preparations, through food handlers, surfaces, or equipment (Rousseau et al., 2018). There are 22 species currently known, the most common that causes human infection are the Cryptosporidium parvum and Cryptosporidium hominis (Vanathy et al., 2017).

Cryptosporidium has a worldwide distribution (Vanathy et al., 2017), and is endemic in developing countries. The prevalence ranges from $4 \%$ to $22.8 \%$ in south American developing countries such as Brazil and Venezuela (Vanathy et al., 2017). Is one of the leading causes of diarrheal and mortality induced by protozoan pathogens worldwide. Adults and children with human immunodeficiency virus (HIV) infection are more prone to suffer from this disease.

Cryptosporidium oocyst is a spherical or slightly ovoid structure measuring 4 to 6 microns in diameter. It has a double wall and an internal structure formed by 4 vermiform sporozoites and residual bodies that are not clearly visible (Chique, 2020).

Cryptosporidium spp. completes its lifecycle in a single host. After ingestion of the oocyst, excystation occurs in the gut followed by the release of sporozoites. It causes infection of the epithelial cells, but it is confined to intracellular and extracytoplasmic location termed as "parasitophorous vacuole." Here, it undergoes two generations of merogony forming eight and four merozoites, respectively. The second stage of merogony is followed by the sexual developmental stage, forming microgamont and macrogamonts. The microgamete fuses with the macrogamete to form a zygote and this develops into an oocyst with four naked sporozoites. There are two types of oocyst, thin-walled and thick-walled oocysts. The former is responsible for autoinfection and the latter persists in the environment for longer periods (Vanathy et al., 2017).

Cryptosporidium spp. cause mild to severe recurrent diarrhea, stomach pain and vomiting, or intestinal disorders, is one of the four pathogens involved in most of the cases of diarrhea in chil- dren younger than 5 years in low-income countries (Rousseau et al., 2018; Berrouch et al., 2020).

An initial macroscopic examination should be done to look for the consistency of the stool, where flotation and concentration techniques are used (Sheather's sucrose, zinc sulfate, and saturated sodium chloride). Specific anti-Cryptosporidium IgG, IgM, or both can be detected by using ELISA. Other techniques used include: immunochromatographic method, polymerase chain reaction (PCR), microsatellite analysis, and fluorescent in situ hybridization (FISH). The diagnosis of extraintestinal cryptosporidiosis (biliary cryptosporidiosis) is done by ultrasonography, where the technician will look for bile duct wall thickening and gallbladder dilatation. The endoscopic retrograde cholangiopancreatography (ERCP) it is the most sensitive of all the methods of diagnosis, it has to be performed in cases where there is high suspicion of biliary disease, but the ultrasound is normal. ERCP may show a papillary stenosis with intrahepatic sclerosing cholangitis. Serum aminotransferases and alkaline phosphatase levels will be elevated (Rousseau et al., 2018; Vanathy et al., 2017).

Chemotherapy treatments include macrolide antibiotic, aminoglycoside paromomycin, ionophores such as maduramycin, rifaximin, octreotide, as well as immunotherapy. Nitazoxanide is found to be useful in immunocompetent patients and it is a licensed drug (Rousseau et al., 2018).

\section{Entamoeba histolytica}

The genus Entamoeba contains a group of unicellular, anaerobic, and parasitic organisms found in humans, primates, and other species of vertebrates of worldwide distribution. Entamoeba species that can be found in the intestinal lumen of humans include E. histolytica, E. dispar, E. moshkovskii, E. coli, E. hartmanni, E. polecki, and E. bangladeshi. E. gingivalis is mainly found in the human oral cavity, but it has also been found in the genitourinary tract, while E. nuttalli prevails in primates (Cui et al., 2019).

Amebiasis or amoebic dysentery is a common parasitic enteral infection, which is caused by any of the pathogenic species of the genus Entamoeba (Zulfiqar et al., 2020), whose pathogenesis is mainly characterized by cytotoxicity, inflammation, and tissue invasion (Shirley et al., 2020). Most infections are asymptomatic, but invasive intestinal disease can occur. Likewise, disseminated extraintestinal disease can also occur, such as liver abscess, pneumonia, purulent pericarditis and even cerebral amebiasis (Kantor et al., 2018).

Currently, amebiasis is the third main cause of disease and the fourth main cause of death from protozoan infections worldwide (Kantor et al., 2018; Debnath, 2015). It is estimated that approximately 500 million people are infected by the parasite worldwide, of which $10 \%$ have invasive amebiasis (Ximénez et al., 2010), with around 100,000 patients dying per year due to clinical complications of the disease (Shirley et al., 2020). Amebiasis is a disease of global importance that occurs mainly in developing countries, 
where hygiene and access to sanitation are inadequate (Shirley et al., 2018). The areas with the highest infection rate, in which the disease is endemic, include Central and South America, Africa, and Asia (Kantor et al., 2018). In developing countries, the exact burden of amoebiasis is difficult to quantify. Reports can be affected by geographic region, study design, sample size, incubation, severity of symptoms, and the sensitivity of the diagnostic tools used (Shirley et al., 2018).

E. histolytica exists in two forms: the infectious cyst form, which give rise to the tissue-invasive trophozoite form. Cysts are relatively resistant and can survive outside the body long enough to be ingested. In contrast, motile trophozoites that are shed with diarrheal or dysenteric feces can survive only briefly outside the body and are destroyed by gastric secretions, thus having no role in transmission (Shirley et al., 2020).

The life cycle of $E$. histolytica is relatively simple, composed of two stages, existing as an infectious cyst or an invasive trophozoite. Transmission occurs after ingestion of the infectious cyst, through hands, food, or water contaminated with fecal matter (Shirley et al., 2018). After ingestion, excystation occurs in the small intestine with the release of motile trophozoites, which migrate to the large intestine. Through binary fission, trophozoites form new cysts, and both stages are shed in the feces. Various properties of the cyst confer it its resistance to adverse environmental factors for weeks, being this stage the transmissive one (Kantor et al., 2018). While trophozoites do not survive outside of the host (Shirley et al., 2018), they do have the ability to adhere and lyse the colonic epithelium and subsequently spread through the portal vein system to distant sites such as the peritoneum, liver, lung or brain (Kantor et al., 2018). Symptoms can appear as soon as several weeks after ingestion but can also show up years after acquiring the infection (Shirley et al., 2018).

Amebiasis can be asymptomatic, known as luminal amebiasis; or it can lead to the development of a serious infection with amoebic colitis and amoebic liver abscess (Shirley et al., 2018). Approximately $90 \%$ of people will remain asymptomatic after ingestion of the infectious amoebic cyst and most will eventually clear the parasite (Shirley et al., 2020), the other $10 \%$ progress to develop a symptomatic infection (Shirley et al., 2018). Symptoms can develop after an incubation period that can be as short as 2 to 4 weeks. Diarrhea is the most common manifestation of the disease, followed by dysentery and very rarely can progress into extraintestinal abscess (Shirley et al., 2020).

Intestinal amebiasis presents as a spectrum of diseases ranging from acute amoebic dysenteric colitis to more chronic non-dysenteric colitis that presents sub acutely with non-specific watery diarrhea (Shirley et al., 2020). Amoebic colitis generally has a subacute onset, with symptoms that can range from mild diarrhea to severe dysentery, with abdominal pain and watery or bloody diarrhea, and weight loss (Shibayama et al., 2015; Kantor et al., 2018; Shirley et al., 2018). Unusual but serious complications can occur, such as fulminant necrotic colitis, whose fatality ranges from
$40 \%$ to $89 \%$ (Shirley et al., 2018), toxic megacolon, and fistulizing perianal ulcers, especially when diagnosis and treatment are not timely. Exclusion of inflammatory intestinal disease is exceptionally important, since misdiagnosis and corticosteroid treatment can lead to these serious complications (Kantor et al., 2018). Amebic liver abscess can occur in the presence or absence of intestinal symptoms, and is the most common extraintestinal manifestation of amebiasis, which develops when trophozoites spread to the liver. Onset can be insidious, subacute, or acute. Symptoms include fever, cough, respiratory symptoms, epigastric pain, pleuritic pain, hepatomegaly with pinpoint liver tenderness, prominent weight loss with less fever and abdominal pain (Shirley et al., 2018; Shirley et al., 2020). Pleuropulmonary amebiasis is the most common complication of amoebic liver abscess (Kantor et al., 2018) and can present in the form of pneumonitis, lung abscess or broncho hepatic fistula (Shirley et al., 2020). Occasionally, trophozoites can also spread via bloodstream to the central nervous system (Shirley et al., 2018) causing cerebral amebiasis, which has an abrupt onset and rapidly progresses to death over 12 to 72 hours without adequate therapy (Shirley et al., 2020).

Differential diagnosis in amoebiasis is extremely important for two aspects: 1) to differentiate amoebic colitis from a bacterial enteric infections, such as those caused by Salmonella spp., Shigella spp., Campylobacter spp., enterohemorrhagic E. coli, enteroinvasive E. coli, Clostridium difficile, as well as other non-infectious causes of colitis (Shirley et al., 2018); and 2) to differentiate it from other Entamoeba species, since $E$. histolytica is morphologically indistinguishable from $E$. dispar and $E$. moshkovskii, which are considered non-pathological species (Nair et al., 2015; Kantor et al., 2018 ). Tools for E. histolytica accurate diagnosis include microscopy, serology, antigen detection, molecular biology techniques and colonoscopy with histological examination (Kantor et al., 2018; Shirley et al., 2018; Shirley et al., 2020).

Since there is currently no vaccine against amebiasis, current therapy for clinical disease requires treatment with two types of drugs: 1) tissue amebicides, such as metronidazole and tinidazole (Nagaraja \& Ankri, 2019), which are very effective in eliminating invading trophozoites and remain the recommended therapy for amoebic colitis and amoebic liver disease (Shirley et al., 2018); and 2) luminal amebicides such as paromomycin, to eliminate intraluminal cysts (Kantor et al., 2018), and prevent invasion and transmission (Shirley et al., 2018). However, concerns about adverse effects and the possible appearance of $E$. histolytica resistant strains have led to the development of new therapeutic strategies against amebiasis. These strategies include improving the potency of existing amebicides, discovering new uses for approved drugs, developing vaccines, and the use of probiotics and bioactive natural products (Nagaraja \& Ankri, 2019). A notable discovery was the amebicidal activity of auranofin, an anti-arthritic phosphine gold compound approved by the Food and Drug Administration (FDA), which proved to be ten times more potent against $E$. histolytica than metronidazole, offering a promising drug repurposing oppor- 
tunity for the treatment of amebiasis (Debnath, 2015). More recent studies have successfully used nitroimidazoles with longer halflives, including tinidazole, secnidazole, and ornidazole, for even shorter periods. A newer potential agent for intestinal amebiasis is nitazoxanide, which has been associated with resolution of $E$. histolytica-related diarrhea in $80 \%$ to $90 \%$ of patients (Shirley et al., 2020). Vaccines are currently being investigated in rodent and non-human primate models and appear promising since protection against intestinal and liver infection has been observed (Kantor et al., 2018). Finally, if fulminant amoebic colitis develops, the patient will require fluid resuscitation and broad-spectrum antibiotics should be administered due to the risk of bacterial translocation (Shirley et al., 2018). Surgical intervention is rarely necessary and is reserved for those patients with signs of acute abdomen or those with toxic megacolon (Kantor et al., 2018).

\section{Trichinella spiralis}

The species of the parasite nematode of the genus Trichinella cause the disease named trichinellosis, which is a zoonotic parasitic disease that results of the consumption of raw or undercooked meat from infected animals (Gottstein et al., 2009). To date, 12 species have been described, which are divided into two clades: 1) the clade of encapsulated species (T. spiralis, T. nativa, T. britovi, T. nelsoni, T. murrelli and T. patagoniensis, T6, T8 and T9) (Krivokapich et al., 2012); and 2) the clade of the non-encapsulated species (T. pseudospirallis, T. papuae and T. zimbawensis) (Karadjian et al., 2020).

Trichinellosis is a parasitic disease characterized by having a wide range of hosts and geographic distribution (Gottstein et al. 2009). According to the World Health Organization (WHO) until 2009 , more than 65,000 cases of trichinellosis were registered around the world, with more than 42 fatal cases (Berger, 2017) in the regions of America, Africa, South Asia, and Europe (Pozio \& Zarlenga, 2013). However, it is estimated that currently 11 million humans in the world are infected with Trichinella species, mainly $T$. spiralis (Berger, 2017). T. spiralis epidemiology characterizes by its compulsory transmission by infected meat consumption (Murrell, 2016).

On the other hand, some authors mention that the importance of $T$. spiralis is mainly economic due to the expensive programs of inspection in pigs, and that the actual public health impact of human trichinellosis is relatively low being the global burden approximately 523 DALYs on 2010 population, of wich $14.5 \%$ of the reported burden was represented by the Americas (Devleesschauwer et al., 2015). However, it is important to remark that in underdeveloped countries, such as those belonging to the neotropics region, small open air pig farms with poor sanitary conditions are common, so the prevalence of Trichinella might be underestimated because of a lack of diagnostic techniques, besides, small outbreaks might remain unrecorded due to limited access to health care (Barennes et al., 2008).
When $T$. spiralis infects a host, its biological cycle begins with the release of $\mathrm{L} 1$ of $T$. spiralis in the stomach, which later invade the small intestine. From 10 to 30 hours post-infection (pi) the L1 will mature into adults and then, approximately one-week pi, male and female mating will produce the newborn larvae (LRN), giving rise to the intestinal phase of the infection. Subsequently, these LRN will migrate mainly through the bloodstream invading the musculoskeletal cells to reach again a L1 stage forming the nurse cell (NC), approximately from 21 to 32 days pi the muscular phase of the infection starts, and thus complete its life cycle (Muñoz-Carrillo et al., 2017a).

The severity of the clinical disease is strongly dependent and directly correlates with the number of $L 1$ ingested, as well as host's age, sex, nutritional, hormonal condition, immunity, and tissue invaded. Likewise, the infection can lead to a wide spectrum of clinical forms, ranging from being an asymptomatic infection to even cause death (Gottstein et al., 2009). The clinicopathology of trichinellosis can be divided based on the phases of the life cycle and/or stages of $T$. spiralis: 1) intestinal phase: it is clinically manifested by the presence of malaise, headache, diarrhea, nausea, vomiting, abdominal pain, fever, periorbital and/or facial edema, conjunctivitis, fever, headache, skin rashes (Mitreva \& Jasmer, 2006; Gottstein et al., 2009), and a circulating eosinophilia (Despommier et al., 2005); 2) muscular phase: signs and symptoms such as myalgia, arthralgia, headache, periorbital and facial edema, being progressive eosinophilia the most relevant clinical finding of the muscular phase (Laverde et al., 2009). The invasion of the diaphragm and accessory respiratory muscles results in dyspnea (Despommier et al., 2005). Finally, in the chronic phase of the disease, approximately 4 weeks pi, complications such as: encephalitis and secondary infections like bronchopneumonia and sepsis can originate in the host (Gottstein et al., 2009).

Early clinical diagnosis of trichinellosis is quite difficult due to the lack of pathognomonic symptoms and signs, likewise, chronic forms of the disease are not easy to diagnose (Gottstein et al., 2009). When the infection occurs on its epizootic or outbreak form, its diagnosis is easier, however, low-level, or sporadic infections are difficult to diagnose since the clinical features are often common to many other enteric diseases. This calls for a differential diagnosis technique (Bruschi \& Murrell, 2002; Gottstein et al., 2009). The identification of $T$. spiralis $L 1$ in muscle tissue is the positive diagnosis of the disease, any technique used for this objective is included within the so-called Direct Diagnostic Methods (Gajadhar et al., 2009), which are carried out post-mortem and comprises 4 main techniques: 1) plate compression, 2) Polymerase chain reaction (PCR) (Despommier et al., 2005; Gottstein et al., 2009), 3) artificial or enzymatic digestion, and 4) histology (Gajadhar et al., 2009). The detection of the humoral immune response in the host represents solid evidence of contact with the parasite, and the techniques developed for this purpose are included among the Indirect Diagnostic Methods (Laverde et al., 2009), through which antibodies against $T$. spiralis are detected. Other assays include: 
1) Indirect immuno-fluorescence (IFI), 2) Enzyme-linked immunosorbent assay (ELISA), 3) Western Blot (WB) and 4) Micro-immuno-diffusion double (MIDD) (Gajadhar et al., 2009).

Currently there is no specific therapy for trichinellosis, however, the pharmacotherapy used includes the use of antiparasitic drugs such as benzimidazoles, mainly albendazole and mebendazole, which are directed against the parasite, and the use of steroidal anti-inflammatory drugs, such as glucocorticoids, whose purpose is to treat the symptoms produced by the disease (Muñoz-Carrillo et al., 2017a). Recently, studies have reported that treatment with resiniferatoxin (RTX), a vanilloid agonist of the transient receptor potential vanilloid (TRPV)-1 (Carnevale \& Rohacs, 2016) has the potential to down-regulate the production of proinflammatory mediators and cytokines, such as NO, PGE2, IFN- $\gamma$, IL-12, IL-1 $\beta$ and TNF- $\alpha$ in the intestinal phase of $T$. spiralis infection. In addition, RTX was capable to reduce the number of circulating eosinophils as well as reduce intestinal pathology; while, in the muscular phase, RTX significantly decreased the implantation and parasite burden of $T$. spiralis $L 1$, associated with a low humoral response (lgG) (Muñoz-Carrillo et al., 2017b). Although RTX has been shown to have a protective effect against $T$. spiralis infection, more studies are needed to determine its potential as an effective treatment for trichinellosis.

\section{Ascaris spp.}

Ascaris spp. are parasitic nematodes whose eggs can remain infective in the environment for years. Ascariasis, infection with Ascaris spp., results from ingestion of infective eggs. A. lumbricoides nematodes are among the most prevalent human parasites worldwide, infecting $>1$ billion persons globally (Miller et al., 2015). Ascariasis is transmitted through the fecal-oral route; eggs are ingested following contact with contaminated hands, food or soil. Eggs have been found on vegetables, especially in areas where excreta are used in agriculture (Weatherhead et al., 2018). Because adult $A$. lumbricoides and $A$. suum worms are morphologically indistinguishable, there has been much debate as to whether they represent the same or different species. In addition, the extent of natural cross-transmission of worms between pig and human hosts is unclear (Betson et al., 2014).

Approximately one billion people in the world are infected with Ascaris lumbricoides, and more than 60,000 people die from this disease annually, causing an estimated loss of 1.2 to 1.5 disability-adjusted years. It affects mostly tropical and subtropical countries around the world, and it is frequently documented in Sub-Saharan Africa, Latin America, China, and East Asia, commonly in rural populations where sanitation facilities are unsatisfactory (De Lima and Horrall, 2020; Shah and Shahidullah, 2018).

Ascaris lumbricoides is a member of family Ascarididae, phylum Nematoda. It is dioecious, spindle-shaped with creamy-white or yellowish color, and is the largest nematode parasitizing the human intestinal tract. The female reaches from 20 up to 40 centime- ters in length and has a conically pointed posterior end. The males reach size between 15 and 20 centimeters and have a ventrolateral curved, hook-like posterior end (Yeremiev et al., 2017).

Infection occurs when the host ingests eggs from stool-contaminated soil. Once in the duodenum, larvae are released and enter the circulation via the enteric mucosa. Once in the capillaries (venous, arterial, or lymphatic), it reaches the liver via the portal vein and then the lungs within the first week. In the lung, they damage the alveolar membrane and mature in the alveolus. Eventually, the larvae are expectorated and swallowed re-entering the gastrointestinal tract. Once in the small intestine lumen, the larvae mature to adult worms in approximately 20 days. When the adult female and male worms are present, they copulate, and the female can produce up to 200,000 eggs per day, which are later eliminated in the feces to the soil. If appropriate moist, shady, and warm environmental conditions are present, the eggs mature to infective form in two to eight weeks and remain viable for up to 17 months. They can be ingested and restart the infective cycle (De Lima \& Horrall, 2020).

Patients infected with ascariasis can be asymptomatic, only showing long-term manifestations of growth retardation and malnutrition. If symptoms are present, abdominal pain, bloating, nausea, vomiting, anorexia, intermittent diarrhea are the most common manifestations. If the number of larvae passing through the lung is significant, pneumonitis and eosinophilia can be seen (also known as Loeffler syndrome). Symptoms include wheezing, dyspnea, cough, hemoptysis, and fever. In superinfection, adult worms can migrate to tubular structures like the biliary and pancreatic system causing cholecystitis, cholangitis, pancreatitis, small bowel obstruction, volvulus, appendicitis, and intussusception. Children are more susceptible to complications than adults (De Lima \& Horrall, 2020).

The best diagnostic test is still the stool exam for ova and parasites, searching for large oval brown trilayered eggs with a mamillated coat. Stool exam can be negative, while the worm migrates and matures (approximately one month). A complete blood count can show eosinophilia during the active migration phase from the intestine to the lungs and larvae can be found in the sputum. Abdominal $\mathrm{x}$-rays can be sensitive but not specific when a whirlpool sign is present. Ultrasound and CT scan can be used to identify worms in the biliary duct and gallbladder (De Lima \& Horrall, 2020). Albendazole $400 \mathrm{mg}$ as a single dose is the drug of choice. The second choice of treatment is mebendazole $100 \mathrm{mg}$ twice a day for three days or ivermectin 100 microgram $/ \mathrm{kg}$ to 200 microgram $/ \mathrm{kg}$ once. In pregnancy, piperazine $50 \mathrm{mg} / \mathrm{kg} /$ day for five days is the drug of choice. Treatment should be repeated after one to three months (de Lima \& Horrall, 2020).

\section{Trypanosoma cruzi}

Chagas disease (CD) is a potentially fatal disease caused by the protozoan Trypanosoma cruzi (T. cruzi) (WHO, 2020), discovered 
by the Brazilian doctor Carlos Justiniano Ribeiro das Chagas (1879 - 1934) (Belaunzaran, 2015), which it is usually transmitted by several species of triatomids which serve as vectors. Murillo-Godínez in 2018 mentions that there are 130 species of triatomids in the world, and 34 of those exist in Mexico.

Although, Transmission was traditionally considered almost exclusively vectorborne, other transmission routes have been observed, including foodborne, where the vector is still essential. This transmission occurs when food get contaminated with metacyclic trypomastigotes from either the feces of triatomines or from the whole insect, which are then ingested by humans. Generally, metacyclic trypomastigotes are inactivated by drying or by low moisture content, so drinks such as fruit juices are the most common foodborne transmission vehicles (Robertson et al., 2016).

More than 100 years after its discovery and despite technological advances and socio-demographic changes, this disease continues to be a challenge for health experts, highlighting its existence as a neglected tropical disease (Molina et al., 2016).

The WHO estimated that in 2020 between 6 and 7 million individuals are infected with $T$. cruzi. It is found predominantly in endemic areas of 21 countries in Latin America, where it is transmitted to humans mainly through contact with feces and / or urine of infected blood-sucking triatomine insects. In addition to this, the disease is transmitted in several ways, vertically congenitally from mothers to children, through uncontrolled transfusion and transplants, by ingestion of contaminated food (mainly fruits), and has now been distributed by migratory flows, trade routes, urbanization and emigration, which has globalized its distribution. (Molina et al., 2016). Due to the large number of people who remain undiagnosed or untreated, an estimated 75 million of people are at risk of infection. The flagellated parasitic form of $T$. cruzi is found in the host's circulatory system and is known as trypomastigote. It has a spindle-shaped and elongated appearance of approximately $12-30 \mu \mathrm{m}$ in length; it has a large nucleus in its central wall, a flagellum, and an undulating membrane that surrounds the entire body.

Within the host cells, the trypomastigote becomes amastigote, a vegetative state that is characterized by a rounded shape and no flagellum, its size is approximately 1.5 to $4 \mu \mathrm{m}$ and it usually agglomerates forming tissue nests or also called pseudocysts. Within its life cycle there is an intermediate morphological form called epimastigote, its size is slightly smaller than that of trypomastigote, only $5-7 \mu \mathrm{m}$, it has a fusiform appearance, a small undulating membrane and does not have a flagellum. According to its genetic diversity, $T$. cruzi has been divided into two main lineages $T$. cruzi I and $T$. cruzi ll that vary due to the tissue tropism of the parasite in the host and due to its virulence. T. cruzi I appear to be more infectious and has a higher affinity to heart and skeletal muscle tissues, meanwhile T. cruzi II appears to be more infective and related to liver and spleen tissues (Palmezano et al., 2015).

In the wild, it can infect arthropods and many mammalian species (domestic and wild). When the vector feeds from the blood of an infected mammal, it also ingests the circulating parasite.
In the the intestinal lumen it multiplies and develops into metacyclic trypomastigotes (infective forms) that come out along with the excretions, pass through the skin or mucous membranes and infect the new host. In the new host, they access circulation as blood trypomastigotes and later as amastigotes on its intracellular form, multiplying by longitudinal binary fission within cells of the mononuclear phagocytic system, lymphoid, muscular or nervous tissue and the cycle is completed when the blood trypomastigotes are ingested by the vector (triatomids). The infection in humans is acquired mainly by the transcutaneous penetration of the parasite present in the excreta of infected hematophagous insects (Salaza-Schettino et al., 2016).

It has been identified three phases of this disease: acute, indeterminate, and chronic. The acute phase occurs when the parasite has been inoculated for the first time, it is generally asymptomatic, although it can cause fever and body ache in $5 \%$ of patients. It is believed that $50 \%$ of infected patients will remain in an indeterminate and asymptomatic phase for life, without complications. After a decade or more, 20 to $30 \%$ will present cardiovascular disease with heart failure, arrhythmias, and thrombus embolism, $15 \%$ to $20 \%$ will present mega esophagus and megacolon. When this disease occurs in the mother and child, the repercussions can be catastrophic for both. For vertical transmission, placental infection can occur before the 22nd week of gestation, and/or the baby can be infected during childbirth with the blood of the infected mother. Factors such as intensity of the parasitemia, parasite virulence, maternal and fetal ability to mount a specific immune response and the functionality of the placental barrier have been mentioned important for congenital infection to develop (Ceballos et al., 2017). Currently the diagnostic methods for trypanososmiasis are based on detecting the parasite in tissue or blood, as well as the detection of antibodies or secretory products of the parasite. In the acute phase, the parasite is rarely detected unless symptoms are severe (WHO, 2012). Microscopy observation is possible since the parasite can be found in blood, cerebrospinal fluid, and tissue, this can be achieved by giemsa staining or fresh. T.cruzi can also be cultured in NNN or LIT medium, and a search for the parasite can be carried out in the leucocitic coat and in the sediment resulting from the centrifugation of blood serum (Strout method). Montenegro's intradermal reaction can be performed with leishmanin 53 or the complement fixation reaction (Bordet method), xenodiagnosis or biopsy (Murillo, 2108).

Since 1990, thiazole compounds, inhibitors of the biosynthesis of ergosterol, which is part of the protozoan membrane, have shown promise results since the parasite requires specific sterols (lipopeptidylphosphoglycerol) for its survival and proliferation. Posaconazole showed parasitological cure in murines in both the acute and chronic phases of $\mathrm{CD}$. Other compounds such as posaconnaitoquinones, diamines, nitromidazoles, ruthenium derivatives and complexes have been evaluated, which showed high toxicity. Over the year's consortia have been formed for the discoveries against Chagas. Among the clinical trials carried out in humans for the 
development of new drugs, we highlight: "Clinical trial for the treatment of chronic Chagas disease whit posaconazole and benzinmidazole (BNZ) (Chagazol $囚$ ) and E1224, studies that evaluated posaconazole and ravuvonazole", in this study, it was concluded that these drugs are not effective as single-agent drugs. In 2011, the pediatric formulation of nezinidazole was approved, with a dosage that will allow its administration to young children, reducing side effects (Belaunzaran, 2015). The WHO in 2020 mentions that BNZ and nifurtimox are $100 \%$ effective if administered in the acute phase of the disease (WHO, 2020). The only drugs prescribed are nifurtimos (NF) (lampit@) and benzimidazole (BNZ), (Ragomil()), ROchagan®; Ranadil囚) (Murillo, 2018).

\section{Fasciola hepatica}

Human fascioliasis is a reemerging disease, found in more than 70 countries, there is little information on fascioliasis in humans and its geographical distribution, however it is estimated that there are 17 million people affected by this parasite in the world (Mas-Coma et al., 2018). In Latin America estimations are up to 2.39 million people infected, which $50 \%$ of cases resides in Bolivia, Ecuador and Peru affecting mainly children (Mas-Coma et al., 2020). The principal disease is caused by $F$. hepatica, a worldwide distributed zoonotic trematode that affects mainly herbivorous mammals, but it can also affect humans. It has a deep economic impact, since it affects productive species such as cattle, sheep, horses, and pigs, reaching losses approximate to 3 million dollars worldwide (Ojeda et al., 2020; Mehmood et al., 2017; WHO, 2018; Mas-Coma et al., 2020). It is generally transmitted by the ingestion of encysted metacercaria attached to vegetation or located at the bottom of freshwater ponds. One of the most common ways of contagion is the ingestion of raw watercress, alfalfa, or lettuce (Estrada et al., 2020; Mas-Coma et al., 2020).

Biological cycle is characterized by four stages (miracidium, sporocyst, cercariae and metacercariae) and takes place in two hosts: a gastropod mollusk and a mammal. Infecting metacercariae enter the digestive tract through consumption of contaminated water or raw vegetables. Then penetrate through the oral cavity and lose their covering in the stomach, releasing a small parasite that crosses the intestinal wall, falls into the peritoneum, and migrates towards the liver, feeding on hepatocytes and causing hemorrhagic necrosis, to finally locate in the bile ducts. Two weeks later the parasites reach sexual maturity and begin to egg laying. The non-embryonic eggs pass from the bile ducts to the intestine and exit through the feces (Valero et al., 2006; Mas-Coma et al., 2018). Symptomatology depends on the number of parasites ingested, and in some cases the person can remain asymptomatic. Infection can be acute or chronic, and is characterized by $30-40 \%$ eosinophilia, fever, diarrhea, vomiting, painful hepatomegaly, biliary obstruction, intestinal tenderness, urticaria, irregular fever, and diarrhea (Walker et al., 2006; WHO, 2008).

Confirmatory diagnosis results from egg observation in a stool sample, which must be repeated three times with ten days separation in between analysis. Other signs useful in diagnosis are: Immunological reactions: intradermal reaction, hemagglutination and gel precipitation; Alteration of the hemogram: eosinophilia of 40 to $80 \%$ in initial state that later decreases; And elevated concentration of bilirubin and alkaline phosphatase in cases of bile duct obstruction (Estrada et al., 2020).

Treatments used for several years were: emetine hydrochloride, dihydroemetine and bithionol, which are already withdrawn from the market. Triclabendazole is the most common treatment today. The dose is $10-12 \mathrm{mg}$. / kg. weight of 1 to 2 doses (Estrada et al., 2020; Walker et al., 2006; WHO, 2018).

\section{Conclusion}

The diseases described here are caused by parasitic species and are foodborne infections, resulting from the ingestion of fecal contaminated food or water. Their main carriers are water, fresh fruits, and vegetables, therefore, good hygiene in their manipulation is key to control and eradicate these diseases. Unfortunately, most of the countries located in the Neotropic area are underdeveloped, which accounts for higher poverty numbers, limited education, and the lack of an adequate health system, these impact negatively not only life quality, but also the control and eradication of these important pathologies. Generally, parasitic diseases are asymptomatic, when symptoms appear, they usually present as gastroenteric diseases, making it particularly difficult to have an accurate diagnose and statistics. Although not all these parasitosis are fatal, the biggest problem of the high prevalence of these pathologies is the negative impact on the quality of life. The annual incidence of the main parasitic diseases transmitted by food has been estimated by the Pan American Health Organization (PAHO) to be up to $10 \%$ of the population, with tropical countries being the most affected. Prevention and control measures are fundamental, being pillars the provision of safe water and the sanitary disposal of excreta, in addition to health education: such as hygienic habits and hygienic handling of food.

\section{Conflict of Interest}

The authors declare that they have no known competing financial interests or personal relationships that could have appeared to influence the work reported in this paper.

\section{References}

Agudelo Higuita, N.I., Brunetti, E., McCloskey, C. (2016): Cystic Echinococcosis. J Clin Microbiol, 54(3): 518 - 523. DOI: 10.1128/ JCM.02420-15

Barennes, H., Sayasone, S., Odermatt, P., De Bruyne, A., Hongsakhone, S., Newton, P.N., Dupouy-Camet, J. (2008): A major trichinellosis outbreak suggesting a high endemicity of Trichinella infection 
in northern Laos. Am J Trop Med Hyg, 78(1): 40 - 44

Belaunzaran, M.L. (2015): Enfermedad de Chagas: Globalización y nuevas esperanzas para su cura [Chagasdisease:Globalizationandnewhopeforitscure]. Rev. Argent. Microbiol., 47(2): 85 - 87. DOI: 10.1016/j.ram.2015.04.001 (In Spanish)

Berger, S.A. (2017): Trichinosis: Global Status: 2017 edition. GIDEON Informatics Inc, e-books. ISBN: 978-1-4988-1680-9. pp. 1-114

Berrouch, S., Escotte-Binet, S., Harrak, R., Huguenin, A., Pierre, F. (2020): Detection methods and prevalence of transmission stages of Toxoplasma gondii, Giardia duodenalis and Cryptosporidium spp. in fresh vegetables: a review. Parasitology, 147(5): 516 - 532. DOI: $10.1017 /$ S0031182020000086

Betson, M., Nejsum, P., Bendall, R.P., Deb, R.M., Stothard, J.R. (2014): Molecular epidemiology of ascariasis: a global perspective on the transmission dynamics of Ascaris in people and pigs. J Infect Dis, 210(6): 932 - 941. DOI: 10.1093/infdis/jiu193

Braae, U.C., Devleesschaumer, B., Sithole, F., Wang, Z., WillingHAM, A.L. (2017): Mapping occurrence of Taenia solium taeniosis/ cysticercosis and areas at risk of porcine cysticercosis in Central America and the Caribbean basin. Parasit Vectors, 10(1): 424. DOI: 10.1186/s13071-017-2362-7

BRUSCHI, F., MURRELL, K.D. (2002): New aspects of human trichinellosis: the impact of new Trichinella species. Postgrad Med J, 78(915): 15 - 22. DOI: 10.1136/pmj.78.915.15

BushURA, R. (2019): Review on Hydatidosis in Small Ruminant and its Economic and Public Health Significance. Dairy and Vet Sci J, 11(2): 555808. DOI: 10.19080/JDVS.2019.11.555 808

Ceballos-Palmares, J.C., Cuéllar-Rufino, S., Vázquez-Ortega, M.T., López-Domínguez, J., Romero-Cruz, V., Calderón-GarcIDUEÑAS, A.L. (2017): Inmunología de la Enfermedad de Chagas congénita [Immunology of congenital Chagas disease]. Perinatal Reprod. Hum., 31(3): 144 - 150. DOI: 10.1016/j.rprh.2018.01.001 Chile, N., Clark, T., Arana, Y., Ortega, Y.R., Palma, S., Meja, A., Angulo, N., Kosek, J.C., Kosek, M., Gomez-Puerta, L. A., Garcia, H.H., Gavidia, C.M., Gilman, R.H., Verastegul, M., Cysticercosis Working Group in Peru. (2016): In Vitro Study of Taenia solium Postoncospheral Form. PLoS Negl Trop Dis, 10(2), e0004396. DOI: 10.1371/journal.pntd.0004396

Chique, C., Hynds, P.D., Andrade, L., Burke, L., Morris, D., Ryan, M.P., O'DwyeR, J. (2020): Cryptosporidium spp. in groundwater supplies intended for human consumption - A descriptive review of global prevalence, risk factors and knowledge gaps. Water Res, 176: 115726. DOI: 10.1016/j.watres.2020.115726

CystiTeam Group for Epidemiology and Modelling of Taenia sollUM TAENIASII/CYSTICERCOSIS (2019): The World Health Organization 2030 goals for Taenia solium: Insights and perspectives from transmission dynamics modelling: CystiTeam Group for Epidemiology and Modelling of Taenia solium Taeniasis/Cysticercosis. Gates Open Res, 3: 1546. DOI: 10.12688/gatesopenres.13068.2

Coral-Almeida, M., Gabriël, S., Abatih, E.N., Praet, N., Benitez, W., Dorny, P. (2015): Taenia solium Human Cysticercosis: A
Systematic Review of Sero-epidemiological Data from Endemic Zones around the World. PLoS neglected tropical diseases. 9(7): e0003919. DOI: 10.1371/journal.pntd.0003919

Coral-Almeida, M., Henriquez-Trujillo, A.R., Asanza, S., Erazo, C., Paucar, M., Calvopiña, M. (2020): Assessing the burden and spatial distribution of Taenia solium human neurocysticercosis in Ecuador (2013 - 2017). PLoS Negl Trop Dis, 14(6): e0008384. DOI: 10.1371/journal.pntd.0008384

CUI, Z., LI, J., CHEN, Y., ZHANG, L. (2019): Molecular epidemiology, evolution, and phylogeny of Entamoeba spp. Infect Genet Evol, 75: 104018. DOI: 10.1016/j.meegid.2019.104018

D'Alessandro, A., Rausch, R.L. (2008): New aspects of neotropical polycystic (Echinococcus vogeli) and unicystic (Echinococcus oligarthrus) echinococcosis. Clin Microbiol Rev, 21(2): 380 - 401. DOI: 10.1128/CMR.00050-07

Debnath, A. (2015): Drug Development: Old Drugs and New Lead. In: Nozakı T., Bhattacharya A. (Eds) Amebiasis. Springer, Tokyo. DOI: 10.1007/978-4-431-55200-0_32

De Coster, T., Van Damme, I., Baauw, J., Gabriël, S. (2018): Recent advancements in the control of Taenia solium: A systematic review. Food Waterborne Parasitol, 13: e00030. DOI: 10.1016/j. fawpar.2018.e00030

De Lima Corvino, D.F., Horrall, S. (2020): Ascariasis. [Updated 2020 Mar 16]. In: StatPearls [Internet]. Treasure Island (FL): StatPearls Publishing. Retrieved from: https://www.ncbi.nlm.nih.gov/ books/NBK430796/

Despommier, D.D, Gwadz, R.W, Hotez, P.J, Charles, A.K. (2005): Parasitic Diseases. Fifth edition. Apple Trees Productions. $135-142 \mathrm{pp}$.

Devleesschaumer, B., Praet, N., Speybroeck, N., Torgerson, P.R., Haagsma, J.A., De Smet, K., Murrell, K.D., Pozio, E., Dorny, P. (2015): The low global burden of trichinellosis: evidence and implications. Int J Parasitol, 45(2-3): 95 - 99. DOI: 10.1016/j.jpara.2014.05.006

Dixon, M.A., Braae, U.C., Winskill, P., Walker, M., DevleesschauWER, B., GabRIËL, S., BASÁÑEZ, M.G. (2019): Strategies for tackling Taenia solium taeniosis/cysticercosis: A systematic review and comparison of transmission models, including an assessment of the wider Taeniidae family transmission models. PLoS Negl Trop Dis, 13(4): e0007301. DOI: 10.1371/journal.pntd.0007301

Dubey, J.P., Lago, E.G., Genaro, S.M., Su, C. (2012): Toxoplasmosis in humans and animals in Brazil: High prevalence, high burden of disease, and epidemiology. Parasitology, 139(11): 1375 - 1424. DOI: $10.1017 / S 0031182012000765$

Estrada, P.J., AgREDA, I.S., Rincones, E.G. (2020): Identification of ecological niches of liver fluke in the Guapan and Bayas parishes, Cañar province. Dom. Cien., (3)6: 965 - 980. DOI: 10.23857/ dc.v6i3.1446

Gajadhar, A.A., Pozıo, E., Gamble, H.R., Nöckler, K., Maddox-Hyttel, C., Forbes, L.B., Vallée, I., Rossi, P., Marinculić, A., BoireAU, P. (2009): Trichinella diagnostics and control: mandatory and best practices for ensuring food safety. Vet Parasitol, 159(3-4): 
197 - 205. DOI: 10.1016/j.vetpar.2008.10.063

Garcia L.S. (2017): Diagnostic Medical Parasitology. ASM Press. 381 - 393. DOI: 10.1016/s0169-4758(97)01175-7

Garcia, H.H., Rodriguez, S., Friedland, J.S., Cysticercosis Working GROUP IN PERU (2014). Immunology of Taenia solium taeniasis and human cysticercosis. Parasite Immunol, 36(8): 388 - 396. DOI: 10.1111/pim.12126

GotTsteln, B., Pozıo, E., Nöckler, K. (2009): Epidemiology, diagnosis, treatment, and control of trichinellosis. Clin Microbiol Rev, 22(1): 127 - 145. DOI: 10.1128/CMR.00026-08

Haby, M.M., Sosa Leon, L.A., Luciañez, A., Nicholls, R.S., Reveiz, L., Donadeu, M. (2020): Systematic review of the effectiveness of selected drugs for preventive chemotherapy for Taenia solium taeniasis. PLoS Negl Trop Dis, 14(1): e0007873. DOI: 10.1371/ journal.pntd. 0007873

Heredía, N., García, S. (2018): Animals as sources of food-borne pathogens: A review. Anim Nutr, 4(3): 250 - 255. DOI: 10.1016/j. aninu.2018.04.006

HILL, D., DuBEY, J.P. (2002): Toxoplasma gondii: transmission, diagnosis, and prevention. Clinical Microbiology and infection. 8(10): 634 - 640. DOI: 10.1046/j.1469-0691.2002.00485.x

Kantor, M., Abrantes, A., Estevez, A., Schiller, A., Torrent, J., Gascon, J., Hernandez, R., Ochner, C. (2018): Entamoeba histolytica: updates in clinical manifestation, pathogenesis, and vaccine development. Can J Gastroenterol Hepatol, 2018: 4601420. DOI: 10.1155/2018/4601420

Karadjan, G., Bllska-Zajac, E., Bahn, P. (2020): Species identification of Trichinella originated from various host and different geographical location by MALDI-TOF. Exp Parasitol, 213: 107890. DOI: 10.1016/j.exppara.2020.107890

LARRIEU, E., ZANINI, F. (2012): Critical analysis of cystic echinococcosis control programs and praziquantel use in South America, 1974 - 2010. Rev Panam Salud Publica, 31(1): 81 - 87. DOI: 10.1590/s1020-49892012000100012

LaVerde, L.M., BuIles, L.M., MASSO, C.J. (2009): Detección de Trichinella spiralis en cerdos faenados en dos plantas de beneficio en el municipio de bello [Detection of Trichinella spiralis on slaughtering domestic pigs from two slaughterhouses located in the Municipality of Bello]. Ces. Med. Vet. Zootec., 4(2): $47-56$. DOI: 10.21615/1028 (In Spanish)

Lightowlers, M.W., Garcia, H.H., Gaucl, C.G., Donadeu, M., AbeLE-RIDDER, B. (2016): Monitoring the outcomes of interventions against Taenia solium: options and suggestions. Parasite Immunol, 38(3): 158 - 169. DOI: 10.1111/pim.12291

Marin, A., Mina, L., Zayas, E., Soler, R. (2020): Characterization of bacterial agents isolated in diseases outbreaks transmitted by foods. MediSan, 24(2): $235-251$

Mas-Coma, S., Bargues, M., Valero, M. (2018): Human fascioliasis infection sources, their diversity, incidence factors, analytical methods, and prevention measures. Parasitology, 145(13): 1665 - 1699. DOI: $10.1017 /$ S0031182018000914

Mas-Coma, S., Buchon, P., Funatsu, I.R., Angles, R., Artigas, P.,
Valero, A., Bargues, M.D. (2020): Sheep and Cattle Reservoirs in the Highest Human Fascioliasis Hyperendemic Area: Experimental Transmission Capacity, Field Epidemiology, and Control Within a One Health Initiative in Bolivia. Front Vet Sci, (27): 7. DOI: 10.3389/fvets.2020.583204

Mehmood, K., Zhang, H., Jawad, A., Abbas, Z., Muhammad, I., Aneela, Z.D., Muhammad, H., Mujeeb, U., Yauing, W., Hafiz, I., TariQ, A., Riaz, H., Muhammad, T., Sadaqat, A., Aman, U., Jiakul, L. (2017): A review on epidemiology, global prevalence, and economical losses of fasciolosis in ruminants. Microb Pathog, (109): 253 - 262. DOl: 10.1016/j.micpath.2017.06.006

Miller, L.A., Colby, K., Manning, S.E., Hoenig, D., McEvoy, E., Montgomery, S., Mathison, B., de Almeida, M., Bishop, H., Dasilva, A., SEARS, S. (2015): Ascariasis in humans and pigs on small-scale farms, Maine, USA, 2010 - 2013. Emerging infectious diseases. 21(2): 332 - 334. DOI: 10.3201/eid2102.140048

MitreVA, M., JAsmer, D.P. (2006): Biology and genome of Trichinella spiralis. WormBook. 23: $1-21$

Molina, I., Salvador, F., Sánchez-Moltalvá, A. (2016): Actualización en enfermedad de Chagas [UpdateChagasdisease]. Enferm Infecc Microbiol Clin, 34 (2): 132 - 138. DOI: 10.1016/j.eimc.2015.12.008 (In Spanish)

MURRELL, K.D. (2016): The dynamics of Trichinella spiralis epidemiology: out to pasture?. Vet Parasitol, 231: 92 - 96. DOI: 10.1016/j. vetpar.2016.03.020

Murillo-GodínEz, G. (2018): Chagas Disease (American Trypanosomiasis). Med. Int. Mex., 34 (6): 959 - 970. DOI: 10.24245/mim. v3462217

Muñoz-Carrillo, J.L., Muñoz-López, J.L., Muñoz-Escobedo, J.J., Maldonado-Tapia, C., Gutiérrez-Coronado, O., Contreras-CordeRo, J.F., Moreno-Garcia, M.A. (2017): Therapeutic effects of resiniferatoxin related with immunological responses for intestinal inflammation in trichinellosis. Korean J Parasitol., 55(6): 587 - 599. DOI: 10.3347/kjp.2017.55.6.587

NagaraJA, S., ANKRI, S. (2019): Target identification and intervention strategies against amebiasis. Drug Resist Updat, 44: 1 - 14. DOI: 10.1016/j.drup.2019.04.003

Nair, G., Rebolledo, M., White, A.C., Crannell, Z., Richards-Kortum, R.R., Pinilla, A.E., Ramirez, J.D., López M.C., Castellanos-Gonzalez, A. (2015): Detection of Entamoeba histolytica by Recombinase Polymerase Amplification. Am J Trop Med Hyg., 93(3): 591 - 595. DOI: 10.4269/ajtmh.15-0276

Ojeda, N.F., González, R., Cornelio, S., Luna, C., Machain, C., TorRES, O.M., CHAY, A. (2020): Factores asociados al decomiso de hígados positivos a Fasciola sp en una zona endémica del sureste de México [Factors associated with the seizure of livers positive to Fasciola sp. in an endemic area of southeastern Mexico]. Rev. mex. de cienc. pecuarias., 11(2): 565 - 575. DOI: 10.22319/rmcp. v11i2.5173 (In Spanish)

Palmezano, J.M., Plazas, L.K., Rivera, K.E., Rueda, V.P. (2015): Enfermedad de Chagas: realidad de una patología frecuente en Santander, Colombia [Chagas disease: reality of a frequent pa- 
thology in Santander, Colombia]. MÉDICAS UIS, 28(1): 81 - 90. DOI: 10.18273/revmed (In Spanish)

Pozio, E., Zarlenga, D.S. (2013): New pieces of the Trichinella puzzle. Int J Parasitol, 43(12 - 13): 983 - 997. DOI: 10.1016/j. ijpara.2013.05.010

Robert-Gangneux, F., Dardé, M.L. (2012): Epidemiology of and diagnostic strategies for toxoplasmosis. Clinical microbiology reviews. 25(2): 264 - 296. DOI: 10.1128/CMR.05013-11

Robertson, L.J., Devleesschauwer, B., Alarcon de Noya, B., Noya Gonzalez, O., Torgerson, P.R. (2016): Trypanosoma cruzi: time for international recognition as a foodborne parasite. PLoS Negl Trop Dis, 10(6): e0004656. DOI: 10.1371/journal.pntd.0004656

Rodriguez-Morales, A.J., Calvo-Betancourt, L.S., AlarcónOlave, C., Bolívar-Mejía, A. (2015): Echinococcosis in Colombia - A Neglected Zoonosis? In: Current Topics in Echinococcosis. IntechOpen. DOI: 10.5772/60731

Rousseau, A., La Carbona, S., Dumetre, A., Robertson, L.J., Gargala, G., Binet, S.E., Favennec, L., Villena, I., Gérard, C., Aubert, D. (2018): Assessing viability and infectivity of food borne and waterborne stages (cyst/oocysts) of Giardia duodenalis, Cryptosporodium spp., and Toxoplasma gondii: a review of methods. Parasite, 25: 14. DOI: 10.1051/parasite/2018009

Salazar-Schettino, P.M., Bucio-Torres, M.l., Cabrera Bravo, M., Fernández-Santos, N.A., Perea-Salazar, M.G. (2016): Enfermedad de Chagas en México [Chagas disease in Mexico]. Rev. de la Fac. de Med. (México), 59 (3): 6 - 16 (In Spanish)

Sander, V., Sanchez, E., Mendoza, L., Ramos, V., Coriglano, G., Clemente, M. (2020): Use of Veterinary Vaccines for Livestock as a Strategy to Control Foodborne Parasitic Diseases. Front Cell Infect Microbiol, 10: 288. DOI: 10.3389/fcimb.2020.00288

ShaH, J., ShaHidullah, A. (2018): Ascaris lumbricoides: A Startling Discovery during Screening Colonoscopy. Case Rep Gastroenterol, $12(2): 224$ - 229. hDOI: 10.1159/000489486

Shibayama, M., de Jesús Serrano-Luna, J., Aguirre-García, J., Tsutsum, V. (2015): Pathology, Pathogenesis, and Experimental Amebiasis. In: Nozaki T., Bhattacharya A. (Eds) Amebiasis. Springer, Tokyo, pp. 411 - 431. DOI: 10.1007/978-4-431-55200-0

Shirley, D.T., FarR, L., Watanabe, K., Moonah, S. (2018): A Review of the Global Burden, New Diagnostics, and Current Therapeutics for Amebiasis. Open Forum Infect Dis, 5(7): ofy161. DOI: 10.1093/ ofid/ofy161

Shirley, D.A., Hung, C.C., Moonah, S. (2020): Entamoeba histolytica (Amebiasis). In: Ryan, E.T., Solomon, T., Endy, T.P., HILL, D.R., ARonson, N.E. (Eds) Hunter's Tropical Medicine and Emerging Infectious Diseases. Amsterdam: Elsevier, p. 699 - 706. DOl: 10.1016/C2016-0-01879-X

Torgerson, P.R., de Silva, N.R., Fèvre, E.M., Kasuga, F., Rokni, M.B., ZHou, X.N., Stein, C. (2014). The global burden of foodborne parasitic diseases: an update. Trends Parasitol, 30(1),: $20-26$. DOI: 10.1016/.jpt.2013.11.002

Torgerson, P., Devleesschaumer, B., Praet, N., Speybroek, N., Lee, A., Kasuga, F., Roknı, T., Zhou, X., Feyvre, E., Sripa, B., Gargourl,
N., Angulo, F., Havelaar, A., Silva, N. (2015): World Health Organization Estimates of the Global and Regional Disease Burden of 11 Foodborne Parasitic Diseases, 2010: A Data Synthesis. PLoS Med, 12(12): e1001920. DOI: 10.1371/journal.pmed.1001920

Trevisan, C., Torgerson, P., Robertson, L. (2019): Foodborne Parasites in Europe: Present Status and Future Trends. Trends Parasitol, 33 (9): 695 - 703. DOI: 10.1016/j.pt.2019.07.002

United States Department of Agriculture Food Safety and INSPECtion Service (USDA): Parasites and Foodborne Diseases. Retrieved August 10 2020. https://www.fsis.usda.gov/wps/portal/ informational/en-espanol/hojasinformativas/enfermedades-por-alimentos/parasitos/parasitos-transmitidas

Valenzuela, M.L., Rico, T.C., Cedillo, P.C., Luna, P.H., Méndez, C.S., Lara, M.G., Correa, D., Caballero, O.H. (2019): Mixed Toxoplasma gondii infection and new genotypes in feral cats of Quintana Roo, México. Acta Trop, 193: 199 - 205. DOI: 10.1016/j. actatropica.2019.03.006

Valero, M.A., DeRenzi, M., Panova, M., Garcia-Bodelon, M.A., Periago, M.V., Ordoñez, D., Mas Coma, S. (2006): Crowding effect on adult growth, pre-patent period and egg shedding of Fasciola hepatica. Parasitology, 133: 453 - 463. DOI: 10.1017/ S003118200600059X

Vanathy, K., Chandra, P.S., Mandar, J., Hamile, A., KrishnmamurTHY (2017): Cryptosporidiosis: A mini review. Trop Parasitol., 7(2): 72 - 80. DOI: 10.4103/tp.TP_25_17

Walker, S., Hoey, E., Fletcher, H., Brennan, G., Fairweather, I., TRUDGETT, A. (2006): Stage-specific differences in fecundity over the life-cycle of two characterized isolates of the liver fluke, Fasciola hepatica. Parasitology, 133(2): 209 - 216. DOI: 10.1017/ S003118200600014X

Wang, Z.D., LIU, H.H., Zhang, X.M., Hung, Y.M., Zhang, Y.L., ZH, B.Y., XING, Q.Z., XU, B., WEI, F., LIU, Q. (2017): Toxoplasma gondii infection in immunocompromised patients: A Systematic Review and Meta-Analysis. Front Microbiol, 8: 389. DOI: 10.3389/ fmicb.2017.00389

Wen, H., Vuitton, L., TuXun, T., LI, J., Vuitton, D.A., Zhang, W., McMAnus, D.P. (2019): Echinococcosis: advances in the 21st century. Clin Microbiol Rev., 32(2): e00075-18. DOI: 10.1128/CMR.0007518

Weatherhead, J.E., Porter, P., Coffey, A., Haydel, D., Versteeg, L., Zhan, B., Gazzinelli Guimarães, A.C., Fujimara, R., Jaramlllo, A.M., BottazzI, M.E., Hotez, P.J., Corry, D.B., Beaumier, C.M. (2018): Ascaris Larval Infection and Lung Invasion Directly Induce Severe Allergic Airway Disease in Mice. Infect Immun, 86(12): e00533-18. DOI: 10.1128/IAI.00533-18

World Health Organization (2008): Fact sheet on fascioliasis. In: Action Against Worms, World Health Organization, Headquarters Geneva (December 2007), Newsletter, 10: 1 - 8

World Health Organization (WHO) (2020): La Enfermedad de Chagas (Tripanosomiasis americana). Datos y Cifras. Retrieved 17 August 2020. https://www.who.int/es/news-room/fact-sheets/ detail/chagas-disease-(american-trypanosomiasis). 
Word Hearth Organization (WHO) (2014): Multicriteria-based ranking for risk management of food-borne parasites. Report of a Joint FAO/WHO Expert Meeting.

Word Hearth Organization (WHO): Ranking basado en múltiples criterios para la gestión de riesgos de parásitos transmitidos por alimentos. 2018. Retrieved August 212020 http://www.fao.org/3/ I3649ES/i3649es.pdf

World Health Organization (WHO) (2018): Renewed medicine donation to sustain global fight against liver infection. Neglected tropical diseases. https://www.who.int/neglected_diseases/news/ renewed-medicine-donation-sustain-global-fight-liver-infection/en/ Word Hearth Organization (WHO): Technical Report /975/ 2012. Research Priorities for Chagas Disease, human African Trypanosomiasis. Italy. Retrieved July 29 2020, http://www.who.int/ bookorde
Ximénez, C., Cerritos, R., Rojas, L., Dolabella, S., Morán, P., Shlbayama, M., González, E., Valadez, A., Hernández, E., Valenzuela, O., Limón, A., PARTIDA, O., SIlva, E.F. (2010): Human amebiasis: breaking the paradigm? Int J Environ Res Public Health. 7(3): 1105 - 1120. DOI: 10.3390/ijerph7031105.

Yeremiev, K., Cvetkova, T., Pavlov, S., Pavlova, K. (2017): Histomorphological characteristics of Ascaris lumbricoides and Taeniarhynchus saginatus. Scripta Scientifica Vox Studentium, 1(1): 32 - 36. DOI: 10.14748/ssvs.v1i1.1788

Zamora, Y.A., Treviño, J., Cuadrado, R.S., Lora, S.F., Gymez, M.J. (2020): Detection and genotypes of Toxoplasma gondii DNA in feces of domestic cats in Colombia. Parasite, 27: 25. DOI: 10.1051/ parasite/2020023

Zulfiqar, H., Mathew, G., Horrall, S. (2020): Amebiasis. In: StatPearls. Treasure Island (FL): StatPearls Publishing; March 4, 2020. 